Research Article

\title{
Mobile Users' Self-Disclosure Behaviour on WeChat: Application of Social Cognitive Theory
}

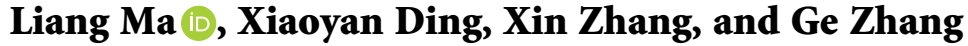 \\ School of Management Science and Engineering, Shandong University of Finance and Economics, Jinan, China \\ Correspondence should be addressed to Liang Ma; maliang1010@126.com
}

Received 14 January 2020; Accepted 28 March 2020; Published 1 August 2020

Academic Editor: L. J. García Villalba

Copyright (c) 2020 Liang Ma et al. This is an open access article distributed under the Creative Commons Attribution License, which permits unrestricted use, distribution, and reproduction in any medium, provided the original work is properly cited.

\begin{abstract}
One of the most challenging issues confronting social media operators is how to increase users' activity and self-disclosure behaviour. However, more and more users are lowering their disclosures on social media, such as WeChat in China. Using social cognitive theory as a starting point while utilizing mobile instant messaging software WeChat as an example, this paper studies the dynamics that influence users' self-disclosure behaviour on WeChat from two aspects: individual factors and environment factors. A structural equation model is used to verify a conceptual model. The results show that, firstly, mobile users' self-disclosure behaviour on WeChat can be affected by both individual factors and environment factors. Specifically, individual factors, such as privacy concerns, negatively affect users' self-disclosure behaviour, while environmental factors, such as social influences, positively affect users' self-disclosure behaviour. More importantly, the research points to significant differences in self-disclosure behaviour between mobile users of different genders and ages. As such, the conclusions of this paper should provide key information for optimized operation of WeChat and other mobile information systems.
\end{abstract}

\section{Introduction}

According to the China Internet Network Information Center (CNNIC), the number of Internet users in China rose to 854 million by June 2019 , with a penetration rate of $61.2 \%$. At the same time, the number of instant messaging users in the country reached 825 million, accounting for $96.5 \%$ of all Internet users [1]. However, among the instant messaging user group, till December 2018, the utilization rate of WeChat friendship circle and QQ space (Tencent Instant Messenger) was $83.4 \%$ and $58.8 \%$, which had dropped by $3.9 \%$ and $5.6 \%$, respectively, compared to the end of 2017 [2]. The social media operators have taken relevant measures to improve user utilization and activity, but the effect is not ideal. Nowadays, mobile information system, represented by WeChat, is developing into an organic platform for "connecting everything." On the one hand, as social media applications grow increasingly rich in information and utility, the influence of social media communication among users is significantly enhanced; on the other hand, the privacy of users in the mobile Internet environment can be seen to be in a rather fragile position, with user concerns about selfdisclosure in social media continuing to increase. According to a survey of 2,000 respondents conducted by the China Youth Daily Social Survey Center, 35.8\% of respondents wanted to close a circle of friends, $19.7 \%$ were planning to close a circle of friends, $13.8 \%$ had closed a circle of friends before, and $2.4 \%$ had already closed a circle of friends [3]. Increasingly, users are aware of the risk to themselves from information disclosure, which in turn reduces information disclosure itself [4]. Considering the significance of selfdisclosure, eliminating mobile users' privacy concerns and encouraging them to upload and disclose personal information in social networks will be of great interest to those developing the functionality of social networks. Therefore, it is both urgent and necessary to explore the influencing factors and motivations of users' self-disclosure behaviour.

This study conducted a literature review of antecedents on social media users' self-disclosure behaviour (Table 1). A review of prior research shows that there have been a number of research studies that have focused extensively on the information disclosure of social media users. In 
TABLE 1: Review of antecedents on social media users' self-disclosure behaviour.

\begin{tabular}{lll}
\hline Source & Media & Antecedents \\
\hline & & \\
$\begin{array}{l}\text { Oghazi et al. } \\
\text { [5] }\end{array}$ & Facebook & Privacy concerns, attitudes, and intentions
\end{tabular}

Privacy intention is the only antecedent that has a significant direct influence on users' self-

[5] Facebook Privacy concerns, attitudes, and intentions disclosure of information. By contrast, neither privacy concerns nor privacy attitude had a statistically significant influence on selfdisclosure

Individuals with high attachment anxiety

Chen et al. [6] Social network sites, such as Sina Weibo

Attachment anxiety, attachment avoidance disclose less personal information on their SNS profile page, while those with high attachment avoidance show a decreased disclosure of profile image on SNS

$\begin{aligned} & \text { Zhang et al. } \\ & \text { [7] }\end{aligned} \quad$ WeChat stress, self-presentation, relationship
maintenance

Li et al. [8] Facebook Social awareness

Walsh et al. $\quad$ Facebook
[9]

Mouakket and Social network sites, Sun [10] such as Renren

Perceived usefulness, habit, subjective norms

WeChat users improve self-disclosure by maintaining relationships and presenting themselves positively in response to role stress Promotion-focused privacy behaviour (i.e., selfdisclosure) is primarily determined by a promotion-related factor (benefits of social awareness), whereas prevention-focused ones

(i.e., privacy management strategies) are primarily determined by prevention-related factors such as privacy concerns

People who perceived their Facebook network as more responsive self-disclosed more openly on Facebook

Perceived usefulness and habit have positive effects on information disclosure, while the effect of subjective norms on information disclosure is not significant

Intrinsic gratifications (entertainment and escapism) and social gratifications (social

Mouakket [11] $\begin{gathered}\text { Snapchat, WhatsApp, } \\ \text { and Skype }\end{gathered} \quad \begin{gathered}\text { Entertainment and perceived escapism. Social } \\ \text { interaction and social influence. Information } \\ \text { sharing and perceived usefulness }\end{gathered}$
interaction) have positive effects on the depth and breadth of self-disclosure via mobile instant messaging apps. Women's self-disclosure is positively affected by social influence, while men are not influenced by this type of gratification

High extroverted and openness people tend to disclose on Facebook a significant amount of personal information, whereas high consciousness and agreeableness users are less inclined to do so

Subjective norm and benefits positively affect Wirth et al. [13]

Social networking sites Subjective norm, benefits, and perceived risk

$\begin{aligned} & \text { Kroll and } \\ & \text { Stieglitz }[14]\end{aligned} \quad$ Facebook
Perceived control, trust, and perceived
privacy risk

Liu et al. [15] WeChat Privacy risk, perceived control, role conflict,
habit, and emotion

Mouakket and Sun [16]
Social networking sites
Personality traits, perceived usefulness, and perceived enjoyment, gender self-disclosure, while the effect of perceived risk on self-disclosure is not significant

Discussing the three factors that influence selfdisclosure, perceived control could be addressed more easily with digital nudges than trust or privacy risk

Role conflict positively affects privacy risk, and privacy risk negatively affects self-disclosure.

Role conflict negatively affects perceived control, and perceived control positively affects selfdisclosure

Personality traits affect perceived usefulness and perceived enjoyment, which further influence information self-disclosure. There are significant gender differences 
TABLE 1: Continued.

\begin{tabular}{|c|c|c|c|}
\hline Source & Media & Antecedents & Findings \\
\hline Jiang et al. [17] & $\begin{array}{l}\text { Online synchronous } \\
\text { communications }\end{array}$ & Privacy concerns, social rewards & $\begin{array}{c}\text { Privacy concerns negatively affect users' self- } \\
\text { disclosure, while social rewards positively affect } \\
\text { self-disclosure }\end{array}$ \\
\hline $\begin{array}{l}\text { Taddicken } \\
{[18]}\end{array}$ & Social web & $\begin{array}{c}\text { Privacy concerns, perceived social relevance, } \\
\text { and the number of applications, willingness to } \\
\text { disclose, age }\end{array}$ & $\begin{array}{l}\text { Privacy concerns hardly impact self-disclosure, } \\
\text { but perceived social relevance and the number of } \\
\text { applications used proved important. Users' } \\
\text { general willingness to disclose is most important } \\
\text { when providing sensitive information. Age } \\
\text { negatively affects self-disclosure }\end{array}$ \\
\hline $\begin{array}{l}\text { Cheung et al. } \\
{[19]}\end{array}$ & Facebook & $\begin{array}{l}\text { Social influence, perceived benefits, and } \\
\text { perceived privacy risk }\end{array}$ & $\begin{array}{l}\text { Social influence is the factor that exhibits the } \\
\text { strongest effect on self-disclosure in social } \\
\text { networking sites, followed by perceived benefits. } \\
\text { Surprisingly, perceived privacy risk does not } \\
\text { have any significant impact on self-disclosure }\end{array}$ \\
\hline
\end{tabular}

particular, prior research has mainly studied factors influencing users' self-disclosure from user characteristics, user's internal perception, and users' interests $[5,9,15,19]$. Although scholars have carried out relevant research on users' information disclosure, there are still some major shortcomings. Firstly, some scholars proved that privacy is an important factor that affects users' self-disclosure [17]; however, some scholars also found this relationship was not significant. For example, Oghazi et al. [5] examined Facebook users' self-disclosure behaviour, and results showed that privacy intention is the only antecedent that has a significant direct influence on users' self-disclosure of information. By contrast, neither privacy concerns nor privacy attitude had a statistically significant influence on self-disclosure. Taddicken [18] also confirmed that privacy concerns hardly impact self-disclosure under social web context. Actually, there is still controversy with regard to the relationship between privacy concern and users' self-disclosure behaviour. Secondly, the social media that research focuses on includes Facebook, social network site, and microblogs such as Twitter $[20,21]$. However, few scholars have explored information disclosure behaviour specifically of WeChat users from the privacy concern and social influence perspectives. The difference between WeChat and other instant messaging services lies in the fact that WeChat is a strong tie social platform, while other instant messaging services such as Facebook are weak tie social platforms [22]. The privacy concern and social influence perception between WeChat and other instant messaging services may be different, which may generate different effect on users' selfdisclosure. Given the significance of privacy concern and social influence in the self-disclosure application, it is particularly essential to examine how strong tie social platforms, such as WeChat users' privacy concern and social influence, affect users' self-disclosure. Thirdly, although some scholars examined users' demographic characteristic differences in self-disclosure, most scholars focusing on weak tie social platforms, such as social networking sites and social web $[10,18]$, ignore the differences between WeChat users of different genders and ages in the process of information disclosure.
In order to make up for deficiencies in the research outlined above, this paper explores the factors that affect information disclosure behaviour of WeChat users from the perspective of individuals and the environment, using social cognitive theory as a conceptual basis. Different from others' works, this study tries to study how strong tie social platforms, such as WeChat users' privacy concern and social influence, affect users' self-disclosure, and the moderating role of users' gender and age is also examined. In doing so, firstly, this paper contributes to the mobile information systems self-disclosure literature by clearing the relationship between privacy concern and self-disclosure under strong tie social platforms. Secondly, this paper contributes to the selfdisclosure literature by examining how strong tie social platforms, such as WeChat users' privacy concern and social influence, affect users' self-disclosure. Thirdly, this paper contributes to the self-disclosure literature by examining the moderating role of users' gender and age under strong tie social platforms. Finally, this study also enriches the research scope of social cognitive theory, and its conclusions deepen the understanding of mobile user information disclosure behaviour. From a practical perspective, this study can also provide vital useful reference for WeChat operation and other mobile information system platforms.

\section{Theoretical Basis and Research Hypothesis}

2.1. Social Media Users'Self-Disclosure Behaviour. This study conducted a literature review of antecedents on social media users' self-disclosure behaviour (Table 1). From literature review, we know that prior research has mainly looked at influencing factors of information disclosure, targeting the following three aspects: firstly, some scholars explore the influencing factors of information disclosure from the perspective of user characteristics. The main influencing factors include a user's personality, emotion, gender, and age $[10,23]$. Secondly, some scholars explore the influencing factors of information disclosure from the perspective of a user's internal perception. It is found that trust, perceived risk, and role stress are the most important factors affecting user information disclosure $[4,7]$. Thirdly, some scholars 
explore the influencing factors of information disclosure from the perspective of users' interests. Research shows that the development of interpersonal relationships, perceived benefits, perceived costs, and other important factors affect user information disclosure $[8,24,25]$. In addition, some studies have pointed out that cultural factors, social capital factors, and perceived network responsiveness are also important factors affecting user information disclosure $[9,21]$. However, although prior researches have made important contribution to the mobile information system self-disclosure literature, there is still controversy with regard to the relationship between privacy concern and users' self-disclosure behaviour [5]. One important reason is that most existing researches focused on the weak tie social media platform, such as Facebook [12], ignoring how strong tie social platforms, such as WeChat users' privacy concern, affect users' self-disclosure. How strong tie social platforms, such as WeChat users' privacy concern and social influence, affect users' self-disclosure is still unclear. Thus, different from others' works, this study tries to study how strong tie social platforms, such as WeChat users' privacy concern and social influence, affect users' selfdisclosure.

2.2. Social Cognitive Theory. The social cognitive theory (SCT) was originally put forward by Bandura [26]. It holds that individual behaviour, subjective cognition, and social environment are both dynamic and interactive. Among these concepts, subjective cognition includes two basic elements: self-efficacy and outcome expectancy. Self-efficacy refers to an individual's cognition of his or her ability to act in the process of achieving a specific goal and a degree of selfconfidence in his or her ability. The resultant expectation is a judgment of the individual's possible outcome of his or her own task. The core view of this proposition is that behaviour is influenced by both environmental and individual factors and can be predicted by perception, expectation, and judgment of the environment through individual factors. The main merit of the SCT is the focus on maintenance of behaviour that many other theories do not take in consideration. For this reason, one of the main merits of this paper is including SCT in the development of the proposed model.

As a mature theory, social cognitive theory has been widely used to understand and predict the characteristics of individual and group behaviour and to identify ways that can change those behaviours. However, there are relatively few studies on information disclosure of WeChat users using social cognitive theory. This study focused on the most popular strong tie social media application in China, WeChat. WeChat, first released in 2011, provides multiple mobile services including voice messaging, pictures and text, friend space (Moments), a public platform, and other services [27]. One of the main activities for WeChat uses is interacting with friends and posting status (which is also called information disclosure in this study) in their friend space. Through the framework of social cognitive theory, this paper divides the influencing factors of WeChat users' information disclosure behaviour into individual factors and environmental factors and subsequently explores its impact on users' behaviour. Individual factors mainly includ perceived severity, privacy experience, and privacy concerns, and environmental factors mainly include social influence.

\subsection{Perceived Severity, Privacy Experience, and Privacy} Concerns. With the rapid development of social networks, more and more users communicate and disseminate information through these channels. Social networking adds convenience and entertainment, but it can also bring numerous problems to users' personal information security. A leak of information from more than 50 million users on Facebook attracted widespread attention from users and the media. Collecting and utilizing user privacy information through social networks has become easier, while the risk of user privacy exposure is increasing, and at the same time increasing numbers of users are paying greater attention to personal privacy disclosure. As early as the mid-1980s, Mason [28] proposed that the advent of the information age would lead to four major concerns about the use of information: privacy, accuracy, property, and accessibility. This hypothesis has proved prescient, especially since privacy has become a subject of growing concern in the years since social media became established [29].

In the Internet age, scholars have conducted extensive research on the influencing factors of user privacy concerns from different perspectives and in different fields. With regard to the influencing factors of privacy concerns, the existing research mainly includes three aspects: personal factors, situational factors, and macro factors [30]. Among them, personal factors mainly include gender, personality traits, personal knowledge, attitude, and previous experience $[23,31]$. Situational factors include privacy policy and reward [4]. The macro factors mainly include culture and social relations [32]. Based on the framework of social cognitive theory, this paper explores the influencing factors of privacy concerns from the perspective of individuals. Privacy experience is an important factor that must be weighed when considering users' privacy concerns [33]. Generally speaking, when a user has experienced negative privacy experiences, his or her attention to privacy will greatly increase $[34,35]$. In addition, perceived severity refers to users' judgment of serious consequences caused by threatening safety incidents. When the user perceiving severity is relatively high, users' attention to privacy is often higher [36]. Based on the above, the following assumptions are made:

H1: perceived severity positively affects user privacy concerns

H2: privacy experience positively affects user privacy concerns

2.4. Privacy Concerns and Information Disclosure. With the development of smartphones and the mobile Internet, more and more users publish, browse, and comment on the 
content of WeChat friendship circles on mobile devices [37]. One important part of this is user information release behaviour or, in other words, user self-disclosure behaviour. In this article, information disclosure refers to the range of friends allowed by WeChat users to check a friend's circle. In recent years, with a large number of data applications, public information, and the increase of WeChat friends, increasing numbers of users have minimized disclosure of information and even closed a circle of friends. According to a survey of 2,000 respondents conducted by the China Youth Daily Social Survey Center, $35.8 \%$ of respondents wanted to close a circle of friends, $19.7 \%$ were planning to close a circle of friends, $13.8 \%$ had closed a circle of friends before, and $2.4 \%$ had already closed a circle of friends [3]. Therefore, in order to understand this particular behaviour, it is necessary to explore the influencing factors of WeChat user information disclosure.

Scholars have published relevant research on user information disclosure previously and found that users who care about privacy will be less likely to provide personal information on social networking sites than those who do not $[4,35]$. For example, Jiang et al. [17], based on APCO (Antecedent $\longrightarrow$ Privacy Concern $\longrightarrow$ Outcome) macro model, used structural equation modeling to analyze 251 respondents from online synchronous communications; the results showed that privacy concerns negatively affected users' information disclosure behaviour. However, the privacy paradox suggests that while Internet users are concerned about privacy, their behaviours do not mirror those concerns [18]. Some further studies have also confirmed this relationship. For example, Oghazi et al. [5] examined Facebook users' self-disclosure behaviour, results showed that neither privacy concerns nor privacy attitude had a statistically significant influence on self-disclosure. Thus, there is still controversy with regard to the relationship between privacy concern and users' self-disclosure behaviour. The limitation of existing researches is that most of them focus on the weak relationship social media platforms, such as Facebook. However, the relationship between privacy concerns and information disclosure on strong relationship platforms is still unclear. Taddicken [18] stated that users might not be concerned about privacy invasions when disclosing only within specific user groups such as friends. Generally, on strong tie social platforms, users' privacy concerns may have a negative impact on information disclosure, but this impact is less than that on weak tie social platforms. Thus, this article holds that when WeChat users pay more attention to privacy, their information disclosure activity will be reduced to some extent. Based on the above, the following assumption is made:

H3: privacy concerns negatively affect user information disclosure behaviour on $\mathrm{WeChat}$

2.5. Social Influence and Information Disclosure. Social influence theory examines the influence of teams on individual behaviour. Social influence is caused by the relationship between the two sides, with one side intentionally or unintentionally affecting the other side's behaviour. Social influence includes three particular aspects: compliance, identification, and internalization [38]. Compliance is when people appear to agree with others but actually keep their dissenting opinions private; identification is when people are influenced by someone who is liked and respected, such as a famous celebrity; internalization is when people accept a belief or behaviour and agree both publicly and privately. In recent years, with the rapid increase in use of the Internet, social influence theory has been applied to the study of social networks and social media. It was found that social influence has an impact on the behaviour of social media users [39]. Furthermore, individual users generally tend to adjust their personal behaviour to confirm to group behaviour [40]. For example, Lewis et al. [41] have found that social networking users are more likely to use private profiles if their friends have already adopted them. Some studies have also found that the information disclosure behaviour of social networking users is positively influenced by social influences on Facebook [19]. In the social network environment of WeChat, when social influence theory is applied and when more and more users around users reduce information disclosure or close a circle of friends, personal information disclosure behaviour will be affected to a certain extent. Based on the above, this paper argues that social influence is an important factor affecting the information disclosure behaviour of WeChat users. As a result, the following assumption is made:

H4: social influence positively affects user information disclosure behaviour on WeChat

This paper presents a research model, as shown in Figure 1. The paper in parallel introduces control variables including user's using time, number of users' friends, and update frequency of users' status. The main merit of the SCT is the focus on maintenance of behaviour that many other theories do not take in consideration. For this reason, one of the main merits of this paper is including SCT in the development of the proposed model.

\section{Research Method}

3.1. Questionnaire Design. A questionnaire is used to verify the model, and it consists of two parts. The first part includes the demographic characteristics of the sample, including gender, age, and educational background. The second part has measurements of the variables in the theoretical model. In order to ensure the content validity of the scale that is used, the design of the questionnaire adopts a mature scale that has been utilized in prior studies and modifies it semantically according to the content of this particular study. The measurements include perceived severity (PS), which consists of four items selected from Mohamed and Ahmad's work [36]; privacy experience (PE), which consists of three items of measurement questions selected from Bansal et al.'s work [42]; privacy concerns (PC), which consists of three items of measurement selected from Baek and Morimoto's work [43]; and social influence (SI), which includes two measurement items; and finally Yun et al.'s [44] maturity scale is selected. Finally, information disclosure behaviour 


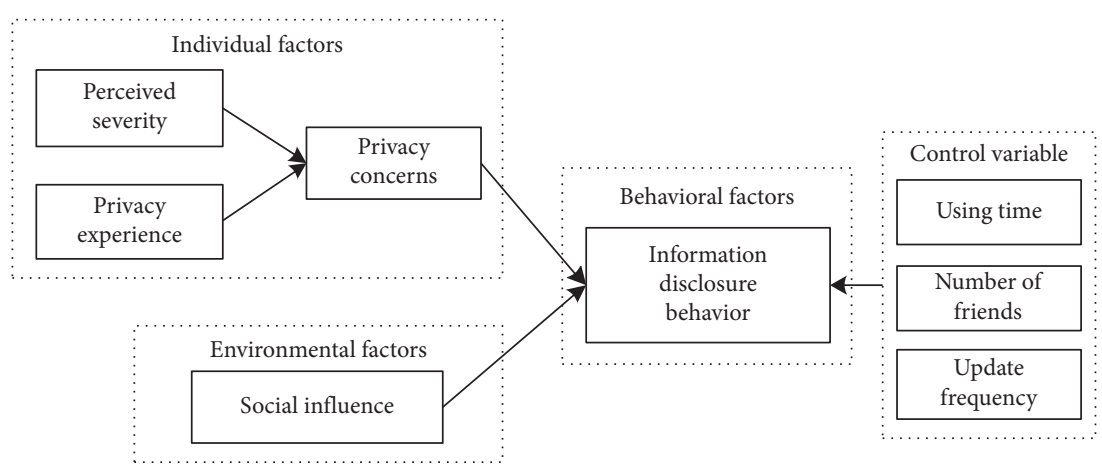

Figure 1: Research model.

TABLE 2: Questionnaire items.

\begin{tabular}{|c|c|c|}
\hline Items & Measurement & Source \\
\hline Perceived severity (PS) & $\begin{array}{l}\text { I think losing privacy information through WeChat is a serious problem for me } \\
\text { Stealing my network identity through WeChat will be a serious problem for me } \\
\text { Losing personal information through WeChat will be a serious problem for me } \\
\text { Losing photo privacy through WeChat will be a serious problem for me }\end{array}$ & {$[36]$} \\
\hline Privacy experience (PE) & $\begin{array}{l}\text { I am the victim of Internet privacy invasion } \\
\text { I used to have bad experiences about privacy on the Internet } \\
\text { I believe that my Internet privacy has been infringed by other people or organizations }\end{array}$ & {$[42]$} \\
\hline Privacy concerns (PC) & $\begin{array}{l}\text { When I use my WeChat, I will worry about my personal information being abused } \\
\text { When I use my WeChat, I worry that I will get unwanted advertisements } \\
\text { When I use my WeChat, I will worry that WeChat will share my information without permission }\end{array}$ & {$[43]$} \\
\hline Social influence (SI) & $\begin{array}{l}\text { Those who can influence me believe that I should reduce information disclosure } \\
\text { People who are very important to me think that I should reduce information disclosure }\end{array}$ & {$[44]$} \\
\hline $\begin{array}{l}\text { Information disclosure } \\
\text { behaviour }(\mathrm{PX})\end{array}$ & $\begin{array}{l}\text { Information disclosure behaviour is measured by the question item: "What range of friends are } \\
\text { allowed to view the circle of friends set by your WeChat." The options for answers to this question } \\
\text { are: "in the last three days," "in the last six months," and "visible at all times." }\end{array}$ & {$[4]$} \\
\hline
\end{tabular}

(PX) is measured by the question item: "What range of friends are allowed to view the circle of friends set by your WeChat." The questionnaire was based on the seven-level Likert scale, where 1 expressed strong disagreement and 7 strong agreement. Actually, the focus of the research is the control of disclosure not self-disclosure $[45,46]$. The specific problems of the scale are shown in Table 2.

3.2. Data Collection. The surveys used in this study were distributed by a Chinese website providing online survey services (http://Soujump.com), and this platform has been used in numerous previous studies for the distribution of questionnaires $[47,48]$. This paper employed the platform to randomly select 281 members from their pool of registered members and then to send e-mail invitations to them to complete the questionnaire. The subjects included WeChat users who were students, enterprise workers, and from other occupations. The reason why we choose WeChat lies in the fact that WeChat was ranked as the fifth largest SNS in the world and the second largest private SNS in the world, becoming one of the world's most popular social media platforms [49]. In China, WeChat is the most widely used social networking site, more than $90 \%$ of mobile phones have installed WeChat, and by the end of 2019, WeChat had over 1 billion active users around the world [50]. Finally, a total of 281 questionnaires were returned, and of these 67 were excluded, which left 214 valid questionnaires. Therefore, the success rate of the questionnaires was $76.16 \%$. The questionnaires recorded the descriptive statistical characteristics of the respondents, such as gender, age, education, and income. At the same time, questionnaires were used to investigate the usage of WeChat, such as time of usage, number of friends, frequency of updating the circle of friends every month, and range of friends allowed to view a circle of friends. The specific descriptive statistics of respondents are shown in Table 3.

\section{Data Analysis}

4.1. Reliability and Validity Analysis. The reliability test using Smart PLS 2.0 shows that Cronbach's Alpha coefficients of all latent variables are greater than 0.7 , indicating that the scale has good reliability. The Composite Reliability (CR) value of each latent variable is greater than 0.7 , which indicates that the measurement model has good internal consistency. The standard load of all measurement items is above 0.5 , and the average extraction variance (AVE) of each latent variable is greater than 0.5 , indicating that the scale has a good convergence validity [51]. The correlation coefficient of the measured variables and the value of the AVE square root are shown in Table 4 . We can see that AVE 
TABLE 3: Descriptive statistics for respondents.

\begin{tabular}{|c|c|c|c|}
\hline Items & Attributes & $N$ & $\%$ \\
\hline \multirow{2}{*}{ Gender } & Male & 88 & 41.12 \\
\hline & Female & 126 & 58.88 \\
\hline \multirow{5}{*}{ Age } & $<20$ years old & 4 & 1.87 \\
\hline & 21-30 years old & 81 & 37.85 \\
\hline & $31-40$ years old & 92 & 42.99 \\
\hline & $40-50$ years old & 29 & 13.55 \\
\hline & $>50$ years old & 8 & 3.74 \\
\hline \multirow{5}{*}{ Income (RMB) } & $<3000$ & 29 & 13.55 \\
\hline & $3001-5000$ & 44 & 20.56 \\
\hline & $5001-8000$ & 74 & 34.58 \\
\hline & $8001-12000$ & 48 & 22.43 \\
\hline & $>12000$ & 19 & 8.88 \\
\hline \multirow{4}{*}{ Usage time of WeChat } & $<1$ year & 9 & 4.21 \\
\hline & $1-3$ years & 65 & 30.37 \\
\hline & $3-5$ years & 90 & 42.06 \\
\hline & $>5$ years & 50 & 23.36 \\
\hline \multirow{3}{*}{ The scope of friends circle } & Last three days & 78 & 36.45 \\
\hline & Half of the year & 59 & 27.57 \\
\hline & Whole & 77 & 35.98 \\
\hline \multirow{4}{*}{ Education } & High school and below & 14 & 6.54 \\
\hline & Junior college & 33 & 15.42 \\
\hline & Undergraduate & 146 & 68.22 \\
\hline & Master's degree or above & 21 & 9.81 \\
\hline \multirow{6}{*}{ Number of friends in WeChat } & $<100$ & 62 & 28.97 \\
\hline & $101-200$ & 68 & 31.78 \\
\hline & $201-300$ & 48 & 22.43 \\
\hline & $301-400$ & 22 & 10.28 \\
\hline & $401-500$ & 10 & 4.67 \\
\hline & $>501$ & 4 & 1.87 \\
\hline \multirow{5}{*}{ Update frequency of friends circle every month } & $1-2$ times & 53 & 24.77 \\
\hline & $3-5$ times & 52 & 24.30 \\
\hline & $6-8$ times & 37 & 17.29 \\
\hline & 9-15 times & 22 & 10.28 \\
\hline & $>15$ times & 50 & 23.36 \\
\hline \multirow{4}{*}{ Work type } & Enterprises and institutions & 91 & 42.52 \\
\hline & Private enterprise & 93 & 43.46 \\
\hline & Student & 20 & 9.35 \\
\hline & Others & 10 & 4.67 \\
\hline
\end{tabular}

TABLE 4: Reliability and validity.

\begin{tabular}{lccccccrr}
\hline Items & Alpha & CR & AVE & PS & PE & PC & SI \\
\hline PS & 0.871 & 0.911 & 0.721 & $\mathbf{0 . 8 4 9}$ & & & & \\
PE & 0.820 & 0.891 & 0.732 & 0.119 & $\mathbf{0 . 8 5 5}$ & & \\
PC & 0.791 & 0.878 & 0.705 & 0.276 & 0.351 & $\mathbf{0 . 8 4 0}$ & \\
SI & 0.708 & 0.749 & 0.599 & 0.482 & 0.089 & 0.166 & $\mathbf{0 . 7 7 4}$ \\
PX & 1.000 & 1.000 & 1.000 & 0.045 & -0.076 & -0.167 & 0.096 \\
\hline
\end{tabular}

Note: PS, perceived severity; PE, privacy experience; PC, privacy concerns; SI, social influence; PX, information disclosure behaviour. The diagonal (bold) elements are the square roots of AVEs, and off-diagonal elements are correlations between constructs.

square root values are greater than the correlation coefficient between the measured variables, indicating that the scale has good discriminatory validity. Finally, Table 5 also shows the factor load and cross factor load of the measurement items. It can be seen that the factor loads of all variables are greater than 0.5 and significant at 0.001 level, and the correlation coefficients between all measurement variables and their potential variables are higher, while the correlation coefficients with other latent variables are lower, further indicating that the measurement items have good distinction and internal consistency.

To make sure that the dataset is free from common method bias, an inspection of Harman's single-factor was conducted. The statistical results in this respect indicated 
TABLE 5: Cross loadings.

\begin{tabular}{lccccc}
\hline Items & PC & PE & SI & PS & PX \\
\hline PC1 & $\mathbf{0 . 8 5 0}$ & 0.269 & 0.034 & 0.230 & 0.208 \\
PC2 & $\mathbf{0 . 7 8 4}$ & 0.248 & 0.282 & 0.254 & -0.185 \\
PC3 & $\mathbf{0 . 8 8 3}$ & 0.356 & 0.125 & 0.046 & -0.123 \\
PE1 & 0.249 & $\mathbf{0 . 8 1 3}$ & 0.058 & 0.061 & -0.066 \\
PE2 & 0.262 & $\mathbf{0 . 8 6 0}$ & 0.020 & 0.169 & -0.164 \\
PE3 & 0.366 & 0.891 & 0.129 & 0.482 & 0.005 \\
SI1 & 0.165 & 0.089 & $\mathbf{0 . 7 7 4}$ & 0.352 & 0.097 \\
SI3 & 0.240 & 0.153 & $\mathbf{0 . 7 7 4}$ & 0.001 \\
PS1 & 0.210 & 0.111 & 0.496 & 0.065 & 0.057 \\
PS2 & 0.261 & 0.086 & 0.417 & $\mathbf{0 . 9 0 6}$ & -0.002 \\
PS3 & 0.256 & 0.053 & 0.318 & $\mathbf{0 . 8 5 4}$ & 0.034 \\
PS4 & 0.202 & -0.076 & 0.431 & 0.828 & 0.045 \\
PX & -0.167 & 0.096 & & 1.000 \\
\hline
\end{tabular}

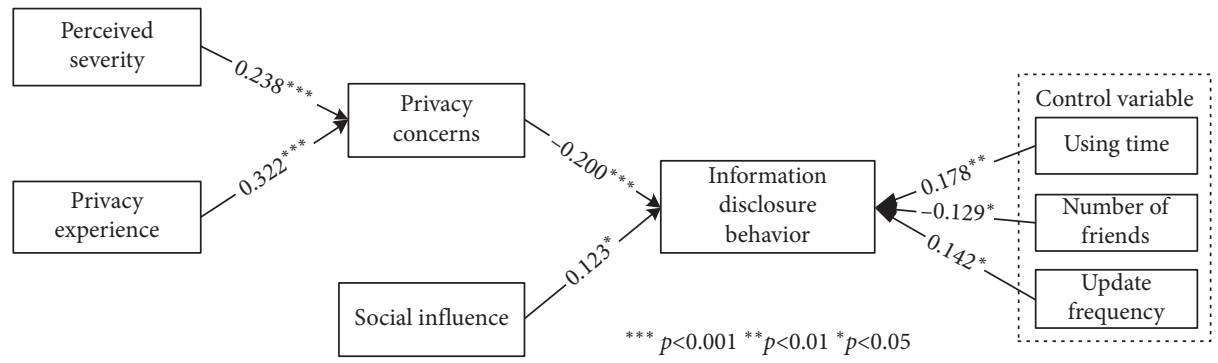

Figure 2: Results of structural equation models.

that no single factor was able to emerge; the highest covariance explained by one factor is $27.845 \%$, which is less than the cut-off value of $50 \%$. Thus, common method bias is not a serious concern [52].

4.2. Structural Equation Model Analysis. This paper uses Smart PLS 2.0 to test the saliency of variables, with the results shown in Figure 2 below. We can see that perceived severity and privacy experience have a significantly positive impact on user privacy concerns. Therefore, propositions $\mathrm{H} 1$ and $\mathrm{H} 2$ are supported. This shows that when the user perceives the seriousness of privacy and has had a bad privacy experience previously, he/she is more concerned about privacy. At the same time, it is found that privacy concerns negatively affect users' information disclosure behaviour. Therefore, proposition $\mathrm{H} 3$ is supported. This shows that where there is more concern regarding a user's privacy, a user's information disclosure behaviour will be lower. Finally, social influence has a positive impact on user information disclosure behaviour. Therefore, $\mathrm{H} 4$ is also supported. This shows that users' information disclosure behaviour will be influenced by their peers. In addition, the results of control variables show that the longer a user engages with WeChat, the higher the frequency of dynamic updating will be. In addition, we can see that a user's information disclosure behaviour will be higher, and the more friends a user has, the lower a user's information disclosure behaviour is likely to be.
4.3. Moderating Effect. This paper adopts the method proposed by Keil et al. [53] to test the moderating effect of gender. First, the samples were divided into two groups according to sex (male and female) and age [54]. Then, the relationship between men and women as well as between younger and older users was also tested. The results are shown in Table 6 . The outcomes of this study suggest that gender differences exist in users' privacy concerns and information disclosure behaviour. Compared with female users, male WeChat users are more likely to generate privacy concerns when they perceive privacy severity and privacy experience. When male users perceive privacy concerns, information disclosure behaviour decreases more significantly. In addition, male users are more likely to be swayed by social influence. Finally, male users are more likely to generate information disclosure behaviour when using WeChat for long time and with a higher frequency of dynamic updating, while female users are less likely to generate information disclosure behaviour with a large number of users' friends.

The results showed that age differences exist in users' privacy concerns and information disclosure behaviour. Younger WeChat users are more likely to generate privacy concerns through perceived privacy severity, while older WeChat users are more likely to generate privacy concerns through privacy experience. When younger users perceive any privacy concerns, information disclosure behaviour decreases more significantly compared to older users, and younger users are more likely to be swayed by social 
TABLE 6: Multigroup test results.

\begin{tabular}{lcccccccc}
\hline Variable & Path & PC1 & PC2 & $\Delta \beta$ & SE1 & SE2 & $T$ & Effect \\
\hline \multirow{2}{*}{ (Group 1: male) } & PS $->$ PC & $0.325^{* *}$ & $0.185^{* *}$ & 0.140 & 0.054 & 0.055 & 18.372 & Male $>$ female \\
& PE $->$ PC & $0.383^{* *}$ & $0.289^{* *}$ & 0.094 & 0.053 & 0.059 & 11.970 & Male $>$ female \\
(Group 2: female) & PC $>$ PX & $-0.202^{* *}$ & $-0.168^{* *}$ & -0.034 & 0.059 & 0.056 & -4.269 & Male $>$ female \\
& SI $>$ PX & $0.205^{* *}$ & $0.110^{*}$ & 0.095 & 0.051 & 0.049 & 13.613 & Male $>$ female \\
\hline \multirow{2}{*}{ (Group 1: younger) } & PS - P PC & $0.318^{* *}$ & $0.212^{*}$ & 0.106 & 0.099 & 0.081 & 8.569 & Younger $>$ older \\
& PE - PC & 0.138 & $0.419^{* *}$ & -0.281 & 0.092 & 0.079 & -23.862 & Older $>$ younger \\
(Group 2: older) & PC - PX & $-0.303^{* *}$ & -0.153 & -0.150 & 0.100 & 0.083 & -11.929 & Younger $>$ older \\
& SI $>$ PX & 0.132 & 0.103 & 0.029 & 0.079 & 0.078 & 2.629 & Younger $>$ older \\
\hline
\end{tabular}

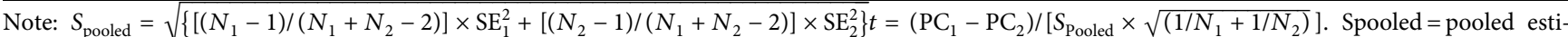
mator for the variance. $t=t$-statistic with $N_{1}+N_{2}-2$ degrees of freedom. $N_{i}=$ sample size of dataset for group $i$. SE $i=$ standard error of path in structural model of group $i$. PC $i=$ path coefficient in structural model of group $i$. O: support; X: no support. Significance levels: ${ }^{*} p<0.05$ and ${ }^{* *} p<0.01$.

influence. Younger users are also less likely to generate information disclosure behaviour with a large number of users' friends; however, no other significant differences were found.

\section{Discussion}

5.1. Key Findings. The purpose of this paper is to study the dynamics that influence users' self-disclosure behaviour on WeChat from two aspects: individual factors and environment factors. The results show that, firstly, perceived severity and privacy experience positively affect users' privacy concerns. Previous studies have shown that user perceived severity and privacy experience have a positive impact on users' privacy concerns in social networking sites $[33,36]$. In the context of existing research, this paper provides evidence that the privacy concerns of WeChat users are also affected by the severity of user perception and user privacy experience. Hallam and Zanella [55] show how a not yet experienced and psychologically distant privacy breach has less weight in everyday choices than more concrete and psychologically near social networking activities. This aligns with our findings, which means the past experience of privacy breaches makes the privacy concerns psychologically concrete, thus reducing the self-disclosure.

Secondly, privacy concerns negatively affect users' information disclosure behaviour on WeChat. Most of the existing studies have explored the relationship between privacy concerns and user information disclosure in social networks and Facebook environments $[18,32]$. In general, some recent cognitive studies on self-disclosure show that privacy-conscious users will make less or no personal information available on social networking sites [17]. The tested model is similar to Jiang et al.'s [17] model (an APCO model) in a study of self-disclosure in the context of online synchronous communications. The similarities between this study and Jiang et al.'s [17] model lie in the fact that we all found that privacy concerns negatively affect users' information disclosure behaviour. However, Jiang et al. [17] considered the effect of social rewards on users' information disclosure in the context of online synchronous communications, while this study investigated users' self-disclosure behaviour on WeChat from the perspective of individual factors and environment factors. Besides, Krasnova et al. [4] found that the effect of privacy concern (risk) on Facebook users' self-disclosure is negative and significant $(\beta=-0.277)$. Vitak [56] also confirmed that the effect of privacy concern on Facebook users' self-disclosure is negative and significant $(\beta=-0.280)$. In this paper, we find that the higher the degree of concern for privacy, the lower information disclosure behaviour of WeChat users $(\beta=-0.200)$. By comparison, this shows that privacy concerns have less impact on information disclosure in strong relationships.

Thirdly, social influence positively affects users' information disclosure behaviour on WeChat. Previous studies have found that individual users tend to adjust their personal behaviour to conform to group behaviour [40]. Cheung et al. [19] found that social influence is the factor that exhibits the strongest effect on self-disclosure in social networking sites. Lewis et al. [41] have found that social networking users are more likely to use private profiles if their friends have already adopted them. Some studies have also found that the information disclosure behaviour of social networking users is positively influenced by social influences on Facebook [19]. In this paper, based on the adoption of social impact theory, we find that when increasing numbers of users reduce information disclosure or close a circle of friends, users' personal information disclosure behaviour will be reduced. In other words, WeChat users' self-disclosure is also positively affected by social influence. One of the possible reasons may be the fact that, under strong tie environment, WeChat users also tend to adjust their personal behaviour to conform to group behaviour (reduce information disclosure).

Finally, the study found that there were significant differences in the information disclosure behaviour of WeChat users with different gender and age. Walton and Rice [57] found that different-gender Twitter users have significant differences in information disclosure behaviour. Jiang et al. [17] did not find a significant effect of gender in the context of online synchronous communications. In this paper, we find that there were significant differences in the information disclosure behaviour of WeChat users with different gender and age. One of the possible explanations may be the platform differences. Jiang et al. [17] focused on online chat rooms, while this study focused on WeChat; there are differences between 
online chat rooms and WeChat. Another possible explanation may be the culture differences. Jiang et al. [17] studied Singapore students, while this study focused on Chinese WeChat users. There may be different culture differences between Singapore and China with regard to information disclosure. Therefore, for WeChat operators, when formulating privacy protection policies, they could take into account the gender and age differences of WeChat users.

5.2. Theoretical Implications. This research contributes multiple theoretical contributions. Firstly, this paper contributes to the mobile information systems self-disclosure literature by clearing the relationship between privacy concern and self-disclosure under strong tie social platforms. Although some scholars proved that privacy is an important factor that affects users' self-disclosure [17], some scholars also found this relationship was not significant $[5,18]$. The privacy paradox also suggests that while Internet users are concerned about privacy, their behaviours do not mirror those concerns [18]. Thus, there is still controversy with regard to the relationship between privacy concern and users' self-disclosure behaviour. The limitation of existing researches is that most of them focus on the weak relationship social media platforms, such as Facebook. However, the relationship between privacy concerns and information disclosure on strong relationship platforms is still unclear. Different from others' works, this study tries to study how strong tie social platforms, such as WeChat users' privacy concern and social influence, affect users' self-disclosure. Results showed that privacy concerns negatively affect users' information disclosure behaviour on the strong tie platforms such as WeChat. The research results deepen the understanding of the relationship between privacy concerns and self-disclosure.

Secondly, this paper extends the social cognitive theory and contributes to the self-disclosure literature by examining how strong tie social platforms, such as WeChat users' privacy concern and social influence, affect users' self-disclosure. In particular, this paper extends the social cognitive theory to the study of social media users' information disclosure behaviour and further expands the scope of social cognitive theory practice. Previous studies on social media users' information disclosure behaviour mainly focused on privacy computing theory, social exchange theory, theory of planned behaviour, use and satisfaction theory, and so on $[58,59]$. Although social cognitive theory has been widely used in different fields, there are few studies on user information disclosure behaviour based on social cognitive theory in social media, especially in the context of WeChat. Furthermore, most existing researches focused on weak tie social platforms, such as Facebook, ignoring exploring how strong tie social platforms, such as WeChat users' privacy concern and social influence, affect users' self-disclosure. Thus, from the perspective of social cognition, this paper explores users' personal information disclosure behaviour on strong tie social platforms, such as WeChat, and the research shows that the WeChat users' personal information disclosure behaviour is negatively influenced by personal factors (privacy concerns) and positively influenced by environmental factors (social influences). The research results contribute a better understanding of outcomes of different privacy perception on users' information disclosure behaviour in extant literatures.

Thirdly, this paper contributes to the self-disclosure literature by examining the moderating role of users' gender and age under strong tie social platforms. To the best of our knowledge, this is the first study to consider the effect of WeChat users' gender and age on privacy perception and information disclosure behaviour in China. Walton and Rice [57] found that different-gender Twitter users have significant differences in information disclosure behaviour. Jiang et al. [17] did not find a significant effect of gender in the context of online synchronous communications. In this paper, we find that there were significant differences in the information disclosure behaviour of WeChat users with different gender and age. In particular, this paper found that male users are more likely to generate privacy concerns when they perceive privacy severity and privacy experience. When male users perceive privacy concerns, information disclosure behaviour decreases significantly. In addition, male users are more likely to be influenced by peer information disclosure, while younger WeChat users are more likely to generate privacy concerns through perceived privacy severity and older WeChat users are more likely to generate privacy concerns through privacy experience. When younger users perceive privacy concerns, information disclosure behaviour decreases more significantly and younger users are more likely to be influenced by social influence. The conclusion of the research conducted is complementary to the existing information of disclosure literature in this area.

5.3. Practical Implications. This study is significant for the operation of WeChat and other social media platforms. Firstly, operators should pay attention to the reduced information disclosure behaviour of WeChat users. Related measures can be taken to prevent this negative behaviour, for example, reduce users' perception of privacy concerns and strengthen the influence of social influences. Secondly, WeChat operators could create a positive security environment to reduce users' privacy risk perception by introducing relevant policies to ensure that users' privacy is not violated. A sound and open information security system could be established, especially with the adoption of data security and personal privacy protection systems, to reduce the occurrence of privacy risks. The operators of WeChat could also take relevant measures to guide users' information disclosure and encourage users to disclose information while creating a good and credible operating environment. Thirdly, WeChat operators could take into account the gender and age differences of WeChat users in formulating privacy protection policies according to our results. Finally, the ultimate goal of our study is not restricted to examining the effect of privacy concerns on users' information disclosure behaviour, but it was to also 
increase awareness of the change in social media users' privacy behaviour. WeChat operators can maintain a long-term cooperative relationship with social media users and achieve a win-win situation, if they adopt this study's recommendations. In doing so, users can still acquire certain knowledge and be entertained, while the operators of WeChat can eliminate users' privacy concerns and encourage users to upload and disclose real personal information in social networks. Other social media operators can also use the conclusion of this paper for their benefit.

5.4. Limitation and Future Research. This paper obtained some valuable conclusions, but the following limitations remain: firstly, the sample size is small with respect to other studies, which may prevent testing the moderating effects in a reliable way. Future research can increase the sample size and strengthen the exploration of boundary conditions. Another limitation is the self-reported nature of the survey, in addition to the (unnamed) external company that collected the data. These can add bias to the measured constructs. Finally, common method variance is a concern in cross-sectional studies [60]. Although we examined common method bias and the results showed that bias was not a major issue, future studies should use quantitative data to actually measure users' cognition and behaviour. At the same time, this paper does not take into account the impact of perceived benefits, perceived costs, self-efficacy, reward, trust, and other factors operating on information disclosure behaviour. Future research can include these other factors in a model to further verify its impact on user information disclosure behaviour.

\section{Conclusion}

The present study tested the self-disclosure behaviour in the context of online strong tie social platform, namely, WeChat. The approach of this study is based on social cognitive theory (SCT) that considers the factors that influence individuals in acquiring and maintaining their behaviour, while also taking into account the social environment in which individuals perform the behaviour. The main merit of the SCT is the focus on maintenance of behaviour that many other theories do not take in consideration. The main merit of this paper is including SCT in the development of the proposed model under strong tie environment. To test our models, this study uses information from a sample of 214 surveys provided by a Chinese online survey service. The results show that information disclosure behaviour of WeChat users is influenced by both personal and environmental factors. Privacy concerns negatively affect a user's information disclosure behaviour, and social influences positively affect it, while perceived severity and privacy experience positively affect a user's privacy concerns. In addition, there are significant differences in information disclosure between users of different gender and age. In summary, this study enriches the scope of application of social cognitive theory, deepens the understanding of user information disclosure behaviour, and can provide useful recommendations for the operation of WeChat.

\section{Data Availability}

The data used to support the findings of this study are available from the corresponding author upon request.

\section{Conflicts of Interest}

The authors declare no conflicts of interest.

\section{Acknowledgments}

This work was supported by the National Social Science Foundation of China under Project no. 17BGL198.

\section{References}

[1] CNNIC, "Forty-four statistical report on the development of China Internet network," 2019, http://www.cac.gov.cn/pdf/ 20190829/44.pdf.

[2] CNNIC, "Forty-three statistical report on the development of China Internet network," 2018, http://www.cac.gov.cn/201902/28/c_1124175677.htm.

[3] C. Y. Daily, " $35.8 \%$ of respondents want to close their circle of friends," 2016, http://it.people.com.cn/n1/2016/0726/c100928584270.html.

[4] H. Krasnova, S. Spiekermann, K. Koroleva, and T. Hildebrand, "Online social networks: why we disclose," Journal of Information Technology, vol. 25, no. 2, pp. 109-125, 2010.

[5] P. Oghazi, R. Schultheiss, K. Chirumalla, N. P. Kalmer, and F. F. Rad, "User self-disclosure on social network sites: a crosscultural study on facebook's privacy concepts," Journal of Business Research, vol. 112, no. 7, pp. 1-10, 2020.

[6] L. Chen, N. Hu, C. Shu, and X. Chen, "Adult attachment and self-disclosure on social networking site: a content analysis of Sina Weibo," Personality and Individual Differences, vol. 138, no. 3, pp. 96-105, 2019.

[7] S. Zhang, R. C.-W. Kwok, P. B. Lowry, Z. Liu, and J. Wu, "The influence of role stress on self-disclosure on social networking sites: a conservation of resources perspective," Information \& Management, vol. 56, no. 7, p. 103147, 2019.

[8] P. Li, H. Cho, and Z. H. Goh, "Unpacking the process of privacy management and self-disclosure from the perspectives of regulatory focus and privacy calculus," Telematics and Informatics, vol. 41, no. 6, pp. 114-125, 2019.

[9] R. M. Walsh, A. L. Forest, and E. Orehek, "Self-disclosure on social media: the role of perceived network responsiveness," Computers in Human Behaviour, vol. 104, no. 3, Article ID 106162, 2020.

[10] S. Mouakket and Y. Sun, "Examining factors that influence information disclosure on social network sites from the perspective of network externalities," Industrial Management \& Data Systems, vol. 119, no. 4, pp. 774-791, 2019.

[11] S. Mouakket, "Information self-disclosure on mobile instant messaging applications: uses and gratifications perspective," Journal of Enterprise Information Management, vol. 32, no. 1, pp. 98-117, 2019. 
[12] B. Caci, M. Cardaci, and S. Miceli, "Development and maintenance of self-disclosure on facebook: the role of personality traits," SAGE Open, vol. 9, no. 2, pp. 1-14, 2019.

[13] J. Wirth, C. Maier, and S. Laumer, "Subjective norm and the privacy calculus: explaning self-disclosure on social networking sites," in Proceedings of the Twenty-Seventh European Conference on Information Systems, Stockholm, Sweden, June 2019.

[14] T. Kroll and S. Stieglitz, "Digital nudging and privacy: improving decisions about self-disclosure in social networks," Behaviour \& Information Technology, vol. 38, no. 2, pp. 1-19, 2019.

[15] Z. Liu, X. Wang, Q. Min, and W. Li, “The effect of role conflict on self-disclosure in social network sites: an integrated perspective of boundary regulation and dual process model," Information Systems Journal, vol. 29, no. 2, pp. 279-316, 2019.

[16] S. Mouakket and Y. Sun, "Investigating the impact of personality traits of social network sites users on information disclosure in China: the moderating role of gender," Information Systems Frontiers, vol. 21, no. 3, pp. 1-17, 2019.

[17] Z. Jiang, C. S. Heng, and B. C. F. Choi, "Research note-privacy concerns and privacy-protective behavior in synchronous online social interactions," Information Systems Research, vol. 24, no. 3, pp. 579-595, 2013.

[18] M. Taddicken, 'The 'privacy paradox' in the social web: the impact of privacy concerns, individual characteristics, and the perceived social relevance on different forms of self-disclosure," Journal of Computer-Mediated Communication, vol. 19, no. 2, pp. 248-273, 2014.

[19] C. Cheung, Z. W. Y. Lee, and T. K. H. Chan, "Self-disclosure in social networking sites: the role of perceived cost, perceived benefits and social influence," Internet Research, vol. 25, no. 2, pp. 279-299, 2015.

[20] R. Chen and S. K. Sharma, "Self-disclosure at social networking sites: an exploration through relational capitals," Information Systems Frontiers, vol. 15, no. 2, pp. 269-278, 2013.

[21] S. Trepte and L. Reinecke, "The reciprocal effects of social network site use and the disposition for self-disclosure: a longitudinal study," Computers in Human Behaviour, vol. 29, no. 3, pp. 1102-1112, 2013.

[22] Y. Wu and M. Wall, "The ties that bind: how the dominance of WeChat combines with guanxi to inhibit and constrain China's contentious politics," New Media \& Society, vol. 21, no. 8, pp. 1714-1733, 2019.

[23] E. Christofides, A. Muise, and S. Desmarais, "Information disclosure and control on facebook: are they two sides of the same coin or two different processes?" CyberPsychology \& Behaviour, vol. 12, no. 3, pp. 341-345, 2009.

[24] K. T. Kwak, S. K. Choi, and B. G. Lee, "SNS flow, SNS selfdisclosure and post hoc interpersonal relations change: focused on Korean facebook user," Computers in Human Behaviour, vol. 31, no. 1, pp. 294-304, 2014.

[25] W. P. Special and K. T. Li-Barber, "Self-disclosure and student satisfaction with Facebook," Computers in Human Behaviour, vol. 28, no. 2, pp. 624-630, 2012.

[26] A. Bandura, "Social foundations of thought and action," Journal of Applied Psychology, vol. 12, no. 1, p. 169, 1986.

[27] C. Gan, "Understanding WeChat users' liking behaviour: an empirical study in China," Computers in Human Behaviour, vol. 68 , no. 3 , pp. 30-39, 2017.

[28] R. O. Mason, "Four ethical issues of the information age," MIS Quarterly, vol. 10, no. 1, pp. 5-12, 1986.
[29] F. Bélanger and R. E. Crossler, "Privacy in the digital age: a review of information privacy research in information systems," MIS Quarterly, vol. 35, no. 4, pp. 1017-1042, 2011.

[30] C. L. Miltgen and D. Peyrat-Guillard, "Cultural and generational influences on privacy concerns: a qualitative study in seven European countries," European Journal of Information Systems, vol. 23, no. 2, pp. 103-125, 2014.

[31] S. S. Wang and M. A. Stefanone, "Showing off? Human mobility and the interplay of traits, self-disclosure, and facebook check-ins," Social Science Computer Review, vol. 31, no. 4, pp. 437-457, 2013.

[32] H. Krasnova, N. F. Veltri, and O. Günther, "Self-disclosure and privacy calculus on social networking sites: the role of culture," Business \& Information Systems Engineering, vol. 4, no. 3, pp. 127-135, 2012.

[33] G. Bansal, F. M. Zahedi, and D. Gefen, "Do context and personality matter? Trust and privacy concerns in disclosing private information online," Information \& Management, vol. 53, no. 1, pp. 1-21, 2015.

[34] Y. Li, "The impact of disposition to privacy, website reputation and website familiarity on information privacy concerns," Decision Support Systems, vol. 57, no. 1, pp. 343-354, 2014.

[35] H. J. Smith, T. Dinev, and H. Xu, "Information privacy research: an interdisciplinary review," Social Science Electronic Publishing, vol. 35, no. 4, pp. 989-1015, 2014.

[36] N. Mohamed and I. H. Ahmad, "Information privacy concerns, antecedents and privacy measure use in social networking sites: evidence from Malaysia," Computers in Human Behaviour, vol. 28, no. 6, pp. 2366-2375, 2012.

[37] L. Ma, X. Zhang, and X. Yan Ding, “Social media users' share intention and subjective well-being: an empirical study based on WeChat," Online Information Review, vol. 42, no. 6, pp. 784-801, 2018.

[38] K. M. White, J. R. Smith, D. J. Terry, J. H. Greenslade, and B. M. Mckimmie, "Social influence in the theory of planned behaviour: the role of descriptive, injunctive, and in-group norms," British Journal of Social Psychology, vol. 48, no. 1, pp. 135-158, 2009.

[39] P. Ifinedo, "Applying uses and gratifications theory and social influence processes to understand students' pervasive adoption of social networking sites: perspectives from the Americas," International Journal of Information Management, vol. 36, no. 2, pp. 192-206, 2016.

[40] R. B. Cialdini and N. J. Goldstein, "Social influence: compliance and conformity," Annual Review of Psychology, vol. 55, no. 1, pp. 591-621, 2004.

[41] K. Lewis, J. Kaufman, and N. Christakis, "The taste for privacy: an analysis of college student privacy settings in an online social network," Journal of Computer-Mediated Communication, vol. 14, no. 1, pp. 79-100, 2008.

[42] G. Bansal, F. M. Zahedi, and D. Gefen, "The impact of personal dispositions on information sensitivity, privacy concern and trust in disclosing health information online," Decision Support Systems, vol. 49, no. 2, pp. 138-150, 2010.

[43] T. H. Baek and M. Morimoto, "Stay away from me," Journal of Advertising, vol. 41, no. 1, pp. 59-76, 2012.

[44] H. Yun, D. Han, and C. C. Lee, "Understanding the use of location-based service applications: do privacy concerns matter?" Journal of Electronic Commerce Research, vol. 14, no. 3, pp. 220-230, 2013.

[45] N. F. Awad and M. S. Krishnan, "The personalization privacy paradox: an empirical evaluation of information transparency 
and the willingness to be profiled online for personalization," MIS Quarterly, vol. 30, no. 1, pp. 13-28, 2006.

[46] E. A. Whitley, "Informational privacy, consent and the "control" of personal data," Information Security Technical Report, vol. 14, no. 3, pp. 154-159, 2009.

[47] M. Liang, Z. Xin, D. Xiaoyan, and W. Gaoshan, "Bike sharing and users' subjective well-being: an empirical study in China," Transportation Research Part A: Policy and Practice, vol. 118, no. 12, pp. 14-24, 2018.

[48] Z. Zhou, J. P. Wu, Q. Zhang, and S. Xu, "Transforming visitors into members in online brand communities: evidence from China," Journal of Business Research, vol. 66, no. 12, pp. 2438-2443, 2013.

[49] G. Zhang, L. Ma, X. Zhang, X. Y. Ding, and Y. P. Yang, "Understanding social media users' unfollow intentions: take WeChat subscriptions as an example," Online Information Review, vol. 43, no. 7, pp. 1081-1097, 2019.

[50] X. Zhang, L. Ma, G. Zhang, and G. S. Wang, "An integrated model of the antecedents and consequences of perceived information overload using WeChat as an example," International Journal of Mobile Communications, vol. 18, no. 1, pp. 19-40, 2020.

[51] J. F. Hair, W. C. Black, B. J. Babin, and R. E. Anderson, Multivariate Data Analysis, Prentice-Hall, Upper Saddle River, NJ, USA, 7th edition, 2009.

[52] X. Zhang, L. Ma, B. Xu, and F. Xu, "How social media usage affects employees' job satisfaction and turnover intention: an empirical study in China," Information \& Management, vol. 56, no. 6, p. 103136, 2019.

[53] M. Keil, B. C. Y. Tan, K.-K. Wei, T. Saarinen, V. Tuunainen, and A. Wassenaar, "A cross-cultural study on escalation of commitment behaviour in software projects," MIS Quarterly, vol. 24, no. 2, pp. 299-325, 2000.

[54] L. Ma, X. Zhang, X. Ding, and G. Wang, "Risk perception and intention to discontinue use of ride-hailing services in China: taking the example of DiDi Chuxing," Transportation Research Part F: Traffic Psychology and Behaviour, vol. 66, no. 7, pp. 459-470, 2019.

[55] C. Hallam and G. Zanella, "Online self-disclosure: the privacy paradox explained as a temporally discounted balance between concerns and rewards," Computers in Human Behaviour, vol. 68, no. 3, pp. 217-227, 2017.

[56] J. Vitak, "The impact of context collapse and privacy on social network site disclosures," Journal of Broadcasting \& Electronic Media, vol. 56, no. 4, pp. 451-470, 2012.

[57] S. C. Walton and R. E. Rice, "Mediated disclosure on twitter: the roles of gender and identity in boundary impermeability, valence, disclosure, and stage," Computers in Human Behaviour, vol. 29, no. 4, pp. 1465-1474, 2013.

[58] Z. Liu, Q. Min, Q. Zhai, and R. Smyth, "Self-disclosure in Chinese micro-blogging: a social exchange theory perspective," Information \& Management, vol. 53, no. 1, pp. 53-63, 2016.

[59] H. Pang, "Microblogging, friendship maintenance, and life satisfaction among university students: the mediatory role of online self-disclosure," Telematics and Informatics, vol. 35, no. 8, pp. 2232-2241, 2018.

[60] P. M. Podsakoff, S. B. MacKenzie, J.-Y. Lee, and N. P. Podsakoff, "Common method biases in behavioural research: a critical review of the literature and recommended remedies," Journal of Applied Psychology, vol. 88, no. 5, pp. 879-903, 2003. 